\title{
A novel de novo TBX5 mutation in a patient with Holt-Oram syndrome
}

This article was published in the following Dove Press journal:

The Application of Clinical Genetics

\section{Lady J Ríos-Serna'}

Lorena Díaz-Ordoñez'

Estephania Candelo ${ }^{1,2}$

Harry Pachajoa ${ }^{1,3}$

'Center for Research on Congenital Anomalies and Rare Diseases (CIACER), Department of Basic Medical Sciences, Universidad Icesi, Cali, Valle del Cauca, Colombia; ${ }^{2}$ Biomaterial and Tissues Engineering and Genetic of Human Diseases, University College London, London, UK; ${ }^{3}$ Fundación Valle del Lili, Cali, Valle del Cauca, Colombia
Correspondence: Harry Pachajoa Center for Research on Congenital Anomalies and Rare Diseases (CIACER), Department of Basic Medical Sciences, L Building, Universidad Icesi, Calle 18 No I22-I35, 76003I, Valle del Cauca, Colombia

Tel +5725552334 Ext 8075

Email hmpachajoa@icesi.edu.co

\begin{abstract}
Holt-Oram syndrome (HOS) is an autosomal dominant disorder characterized by congenital cardiac defects and congenital deformities of the upper limbs. Herein, we report the case of a 2-year-old patient presenting with clinical diagnostic criteria of HOS with interatrial and interventricular communication associated with hip dysplasia and upper limb reduction composed of radial ray anomaly. A novel de novo, potentially pathogenic variant in the TBX5 gene at NM_181486.2:c.243-1G>C was identified.
\end{abstract}

Keywords: Holt-Oram syndrome, heart-hand syndrome, de novo mutation, TBX5

\section{Introduction}

Holt-Oram syndrome (HOS) is an autosomal dominant disorder (MIM: 142900) described for the first time by Holt and Oram in 1959. ${ }^{1}$ The incidence is 1:100,000 live births, and more than 300 cases have been reported with diverse ethnic and geographic distribution. ${ }^{2,3}$ HOS is characterized by congenital deformities of the superior limbs (CDSL) associated with congenital heart defects. ${ }^{4}$ The clinical diagnostic criteria include the presence of a radial ray preaxial anomaly in one of the superior limbs and personal or family history of cardiac defects. ${ }^{5}$ Skeletal defects of the superior limbs can be from bone carpal abnormalities or the triphalangeal thumb to the bilateral phocomelia. ${ }^{6}$ The most common congenital heart defects are the ostium secundumtype atrial septal defects and ventricular septal defects. However, more severe cardiac defects, such as Tetralogy of Fallot or a hypoplastic left heart, have been documented. , $^{7}$

This syndrome is caused by a $T B X 5$ heterozygous mutation localized in the long arm of chromosome 12 (12q24.1). Forty percent of the cases occur due to new mutations, and the remaining cases occur due to familial inheritance. ${ }^{1}$ TBX5 proteins are members of a conserved family of transcription factors that share a common DNA-binding domain called the T-box. ${ }^{8}$ This transcriptional factor is associated with heart and limb development. ${ }^{9}$ TBX5 is expressed in the epicardium, myocardium, and endocardium of embryonic and adult hearts. ${ }^{10}$ In early cardiac development, this transcriptional factor activates genes associated with morphological septation and cardiomyocytes' maturation; later it is involved in the development of the cardiac conduction system. ${ }^{11}$ Studies in animal models indicate that TBX5 is expressed in the forelimb field and is implicated in the initiation of limb outgrowth. ${ }^{12}$

Almost 90 different variants in this gene have been reported, and most of them are results of missense, frameshift, or splice-site mutations, which create truncated proteins 
and generate haploinsufficiency. In addition, these variants may alter the nuclear localization of the protein and its ability to bind to DNA. ${ }^{13-15}$ Some cases have also been reported with chromosomal alterations, such as translocations, deletions, and duplications. ${ }^{13,15} \mathrm{~A}$ mutation in TBX5 has been identified in $70 \%$ of patients with $\mathrm{HOS},{ }^{5}$ with a variable phenotype associated with the mutation type and the localization. ${ }^{17,18}$ Furthermore, other genes, such as SALL4, have also been identified to be associated with disease development. ${ }^{16}$

Herein, we report a novel de novo, potentially pathogenic mutation in the $T B X 5$ gene as a cause of HOS in one patient with clear clinical diagnosis.

\section{Case presentation}

The patient was a Colombian 2-year-old female infant who was a product of non-consanguineous pregnancy and the first and only child of the family. She was born when her father was 34 years old and her mother was 30 years old. She had a family history of seizure syndrome and febrile crisis from the maternal lineage without other important family histories, such as genetic or neurological disorders. No complications were reported during the perinatal care and prenatal studies. She was born through vaginal delivery at 39.5 weeks gesta- tion without any complications, weighed $3.170 \mathrm{~g}(50 \mathrm{th}-75$ th percentile), had a height of $51 \mathrm{~cm}$ (50th-75th percentile), with an Apgar score of 9-10. She was born with multiple CDSL and bilateral phocomelia, shortening of the left arm mainly, syndactyly of the second and third fingers of the left hand, and agenesis of both thumbs (Figure 1). She underwent a period of hospitalization for these multiple malformations.

The patient presented with ostium secundum-type atrial septal defect, muscular ventricular septal defect, and pulmonary hypertension that worsened when she was 6 months old. Due to this worsening, she was placed under pediatric critical care again. The computerized tomography scan showed diffuse cerebral edema with a partial collapse of the ventricular system without other focal lesions such as embolism and bleeding. Magnetic resonance imaging of the brain revealed restriction of generalized diffusion predominantly in the posterior and right areas without ventricular collapse and subdural efflux without compressive effect associated with adjacent cortical changes ascribable to necrosis. The electroencephalogram showed the absence of deep rhythms, severe slowing of the wave registers, and high-voltage bursts. Surgical intervention was provided to close the aortopulmonary and the pulmonary cerclage. After the first surgery, she

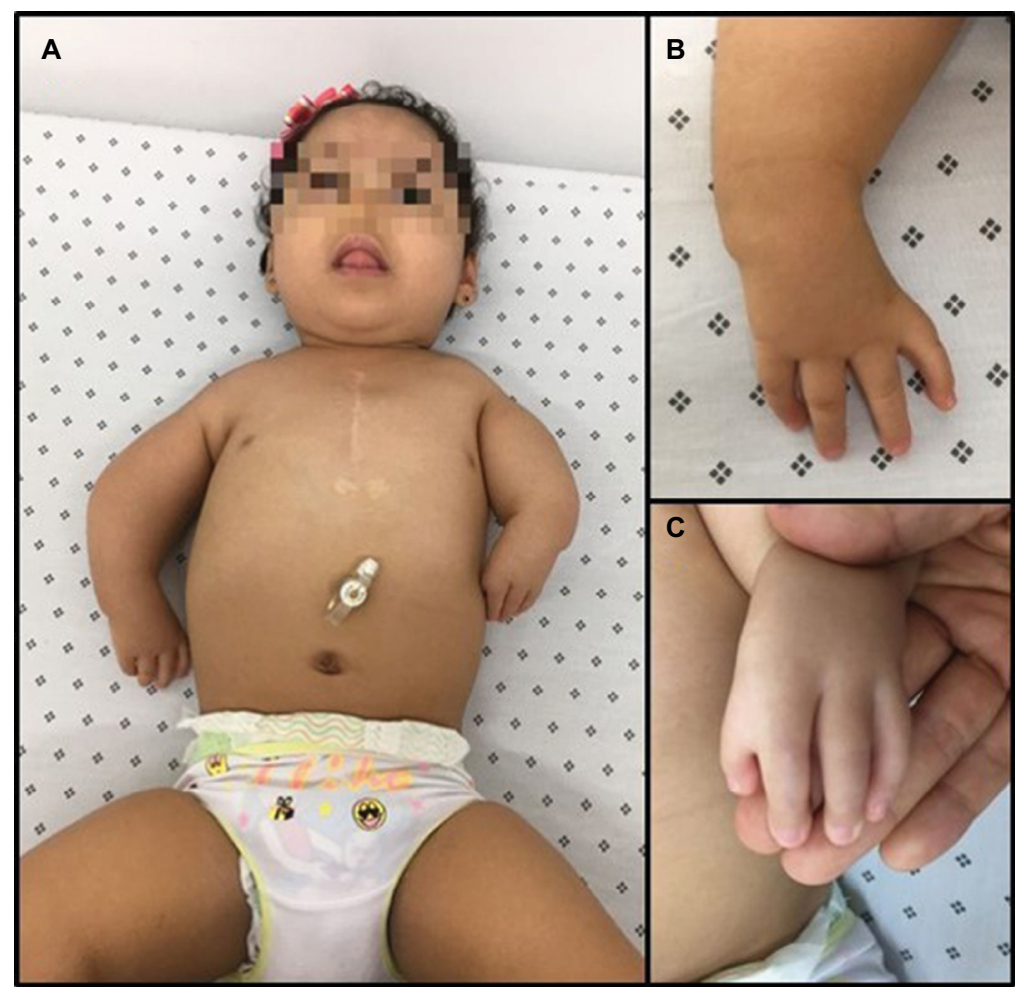

Figure I Morphological abnormalities.

Notes: (A) Body and upper limbs showed shortening of the superior limbs, bilateral phocomelia. (B) Right thumb agenesis. (C) Left thumb agenesis and syndactyly in the second and third fingers of the left hand. 
presented with cerebral edema with encephalopathy due to axonal sprouting after the cortical lesion and generalized hypertonia as a consequence of the motor descending tract lesion, which was treated with clonazepam and phenobarbital without new episodes.

At 14 months of age, she presented with oropharyngeal dysphagia with moderate oral motor skills. For that reason, she received enteral feeding by gastrostomy. An intestinal transit study showed a duodenal corkscrew sign in the second intestinal portion at the Treitz angle level on the right side close to the right pedicle (L1). The image showed that the first jejunal handles were at the right center. All of these findings were related to intestinal malrotation changes. These changes included normal cecum position and gastroesophageal reflux grade III, which reached the barium column up to the proximal region of the esophagus. The follow-up electrocardiogram showed increased signs of sinus rhythm and right ventricular function. In addition, there was evidence of successful modification of the aortopulmonary window and pulmonary cerclage, muscular restrictive interventricular communication with a few left to right shunts, properly biventricular function without overflow, and pulmonary hypertension signs without clots and vegetations.
Radiological studies of the upper limbs revealed absence of bilateral metacarpal bones and phalanges of the first finger, bilateral radioulnar hypoplasia, absence of the ulna in the left arm (Figure 2), hip dysplasia, and femoral-tibial varum angle (genu varum). No radiological changes in the spinal column X-ray were detected.

She was referred for genetic consultation at 2 years of age with a weight of $11.8 \mathrm{~kg}$ (50th-75th percentile), height $88 \mathrm{~cm}$ (75th-90th percentile). She presented with forehead hemangioma and hypoplasia of the nasal bones without appropriate visual follow-up, cephalic support was not successful, trunk and upper limbs were hypotonic, superior limbs with spasticity were more notable on the left side, and nipple hypertelorism.

A complete sequence of the $T B X 5$ gene was generated and compared to the NG_007373.1 (GeneBank) reference sequence which identified a novel potentially pathogenic variant in the heterozygous status NM_181486.2:c.243-1G>C. This splice-site mutation alters the acceptor site of the third intron, which is predicted to affect the splicing and lead to a nonfunctional protein. Using Sanger sequencing, this novel variant was confirmed using an ABI 3500 sequencer (Applied Biosystems, Thermo Fisher Scientific, Waltham, MA, USA). A carrier study in the parents was negative for this mutation (Figure 3 ). For that reason, this mutation was

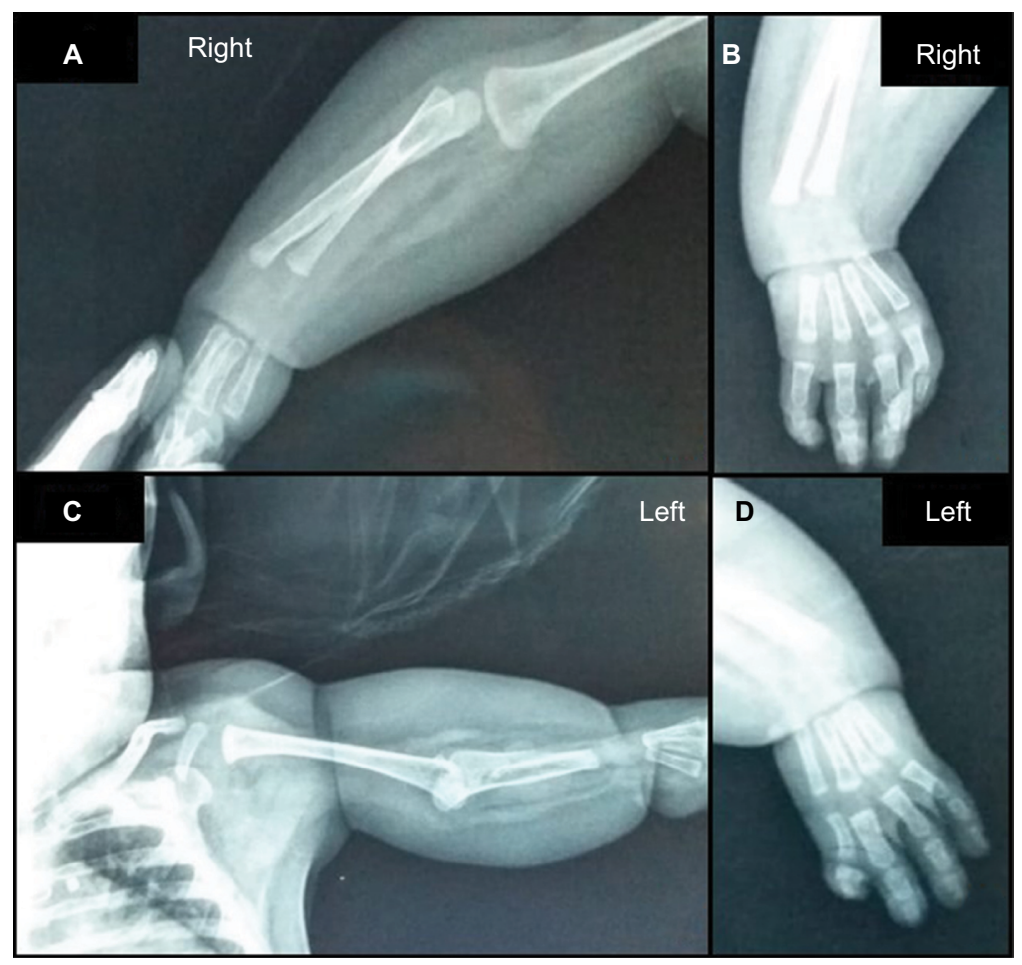

Figure 2 X-ray images of the upper limbs.

Notes: (A) Right upper limbs with radioulnar subluxation in the elbow joint. (B) Right hand with an absence of the first finger, including the metacarpal bones and phalanges. (C) Left upper limbs with an absence of the ulna. (D) Left hand with an absence of the first finger, including the metacarpal bones and phalanges. 
considered to be a novel de novo mutation, which has not been previously reported.

\section{Discussion}

HOS is an autosomal dominant disorder, and in the majority of cases, it is caused by TBX5 mutations. This gene is located in the long arm of chromosome 12 (12q24.1), which codes for TBX5 protein and has a fundamental role in tissue and organ formation during embryonic development. It is involved in the normal development of the upper limbs and heart (structure and electric system) by activating different genes. ${ }^{9,19,20}$ In the present case report, a point mutation in the $T B X 5$ gene was identified in the acceptor site of the third intron, NM_181486.2:c.243-1G>C, which has not been previously reported. Bioinformatic analyses predicted an alteration in the acceptor site, which affects splicing (HSF v 3.1) and is classified as a pathogenic variant according to the ACMG Standards and Guidelines. ${ }^{21}$ Furthermore, this mutation is located in a site of T-box domain that may affect the binding with DNA (Figure 4). In our patient, because none of the family members had morphological anomalies in the upper limbs or heart defects and the carrier studies were negative, a de novo mutation was confirmed.

Our patient meets the HOS criteria described in the literature, ${ }^{5}$ which includes upper limb malformations and heart defects. The patient presented with severe asymmetric radial malformations combined with mild cardiac abnormalities which were corrected by surgical procedures. Superior limb abnormalities can be unilateral or bilateral and asymmetric. They are usually worse on the left side compared to the right side, ${ }^{2}$ which was clearly seen in this case wherein the patient had bilateral malformation predominantly on the left side of the body with the absence of the left ulna and a shortened upper left limb. The absence of the thumb is the most frequent limb abnormality, whereas ulnar abnormalities are less frequent than radius alterations. ${ }^{6}$

Lower limb, craniofacial, pulmonary, genitourinary, and gastrointestinal malformations have been occasionally

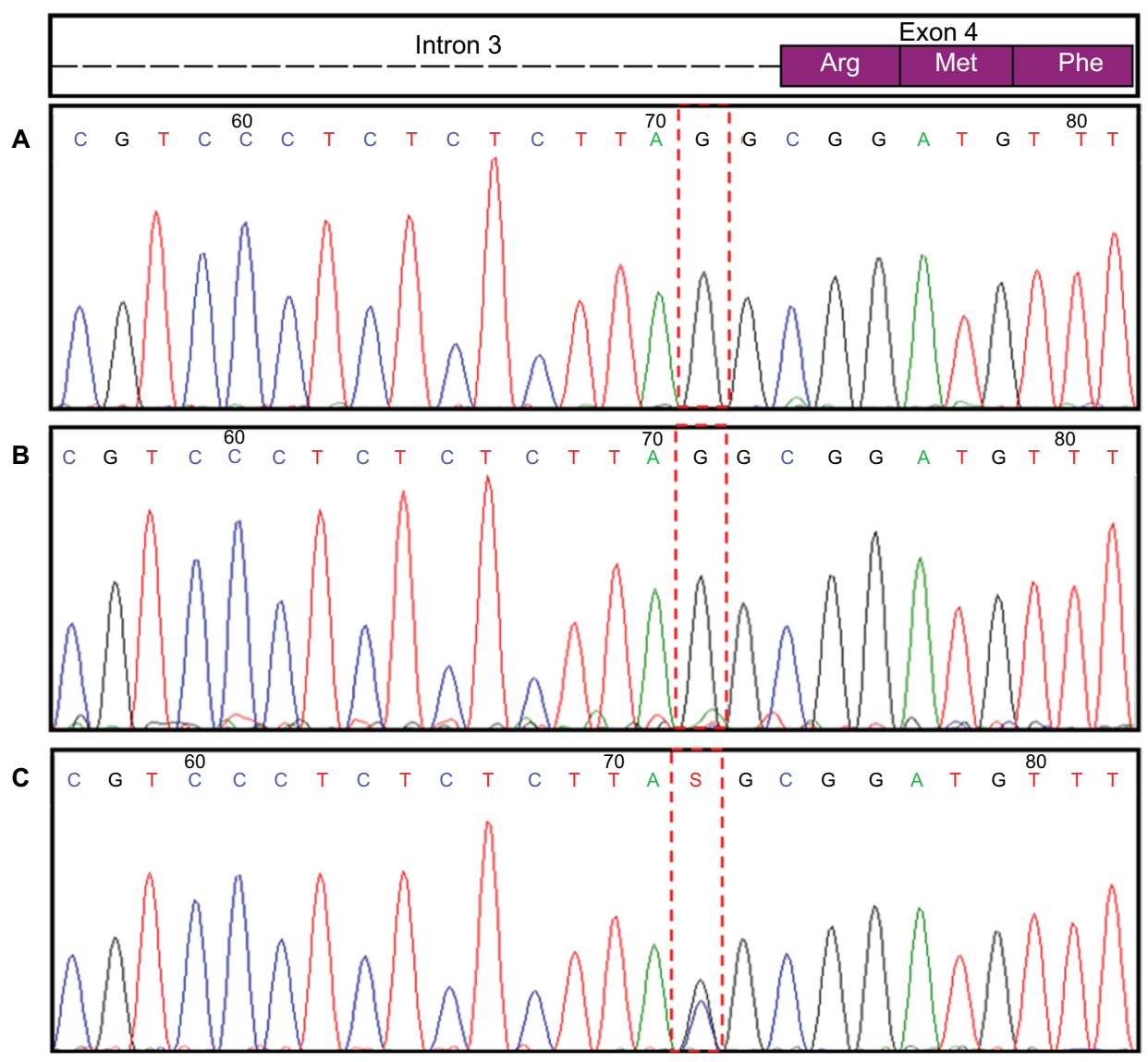

Figure 3 TBX5 gene sequence.

Notes: At the top of the figure it can be observed that intron 4 and exon 5 positions correspond to the nucleotides sequence. The TBX5 gene sequence showed a normal result $(\mathbf{A}, \mathbf{B})$ and heterozygous substitution $\mathrm{G}>\mathrm{C}$ in the 243-I position (NM_I8I486.2:c.243-IG>C) (C), related to HOS. (A) Thirty-seven year-old male (father), (B) 33-year-old female (mother), (C) 2-year-old infant (proband).

Abbreviation: HOS, Holt-Oram syndrome. 


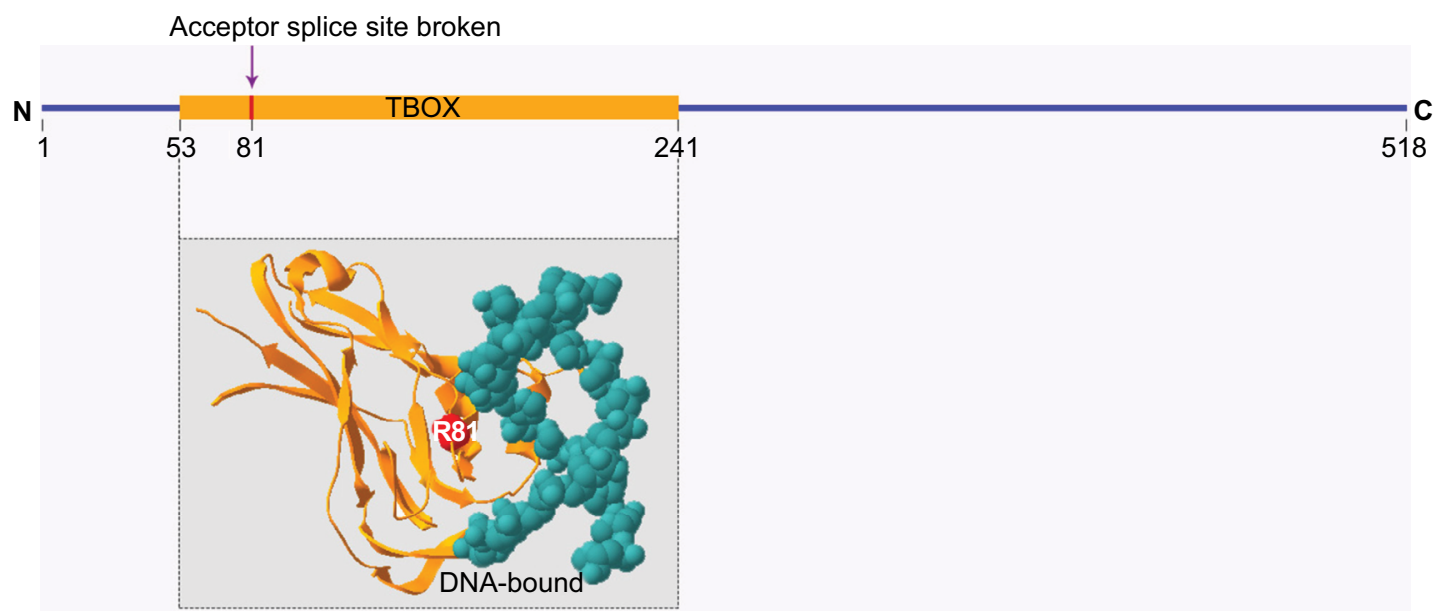

Figure 4 Affected site due to splicing mutation localization of the splice site mutation (NM_I8I486.2:c.243-IG>C) in a site of T-box domain (amino acid 8I, arginine) near DNA binding site.

reported. ${ }^{6,22-24}$ However, they are not the main characteristics of this syndrome. ${ }^{1,17}$ Hip dysplasia is a congenital malformation previously reported in only one patient with $\mathrm{HOS},{ }^{6}$ due to hip malformation being an isolated sign of HOS, it is proposed as a random association and does not eliminate the diagnosis to HOS, as some authors have suggested in previous studies.,25

The radius and ulna can easily be observed between the 13 th and 16th week of gestation, and a majority of congenital defects are visible during routine prenatal care between the 18 th and 20th week of pregnancy. However, more than $60 \%$ of the cases were not suspected during the prenatal follow-up, which was the case in our patient. The different congenital malformations were not detected during pregnancy.

\section{Conclusion}

We identified and reported a novel, potentially pathogenic mutation as a cause of HOS in one patient with clear clinical diagnosis. We also presented an atypical sign of HOS (hip dysplasia), which might not be directly related to the clinical spectrum of this syndrome, but did not exclude HOS diagnosis in this case.

\section{Consent for publication}

Written informed consent was obtained from the patient's parents for publication of her images and clinical data for scientific purposes. Data were collected in the context of studies performed in accordance with the Declaration of Helsinki Good Clinical Guidelines and protocol no 509 "registry of surveillance and survival of congenital defects of the Colombian South-West" approved by the Ethics Committee of Universidad Icesi (Act 192/2011).

\section{Acknowledgment}

We thank the family for being a part of this study.

\section{Disclosure}

The authors report no conflicts of interest in this work.

\section{References}

1. Holt M, Oram S. Familial heart disease with skeletal malformations. Br Heart J. 1960;22(Case 1):236-242.

2. Huang T. Current advances in Holt-Oram syndrome. Curr Opin Pediatr. 2002;14(6):691-695.

3. orpha.net [homepage on the Internet]. Bossert $\mathrm{T}$, Walther $\mathrm{T}$, Gummert J, Hubald R, Kostelka M, Mohr FW. Holt-Oram syndrome. Orphanet Encycl; 2003. Available from: http://www.orpha.net/data/patho/GB/ uk-HOS.pdf. Accessed November 1, 2018.

4. Hurst A, Hall CM, Baraitser M. The Holt-Oram syndrome. J Med Genet. 1991;28(6):406-410.

5. Mcdermott DA, Bressan MC, He J, et al. TBX5 genetic testing validates strict clinical criteria for Holt-Oram syndrome. Pediatr Res. 2005;58(5):981-986.

6. Barisic I, Boban L, Greenlees R, et al. Holt Oram syndrome: a registrybased study in Europe. Orphanet J Rare Dis. 2014;9:156.

7. Sletten LJ, Pierpont ME. Variation in severity of cardiac disease in Holt-Oram syndrome. Am J Med Genet. 1996;65(2):128-132.

8. Weizmann Institute of Science. GeneCards Human Gene Database TBX5 Gene. Available from: http://www.genecards.org/cgi-bin/carddisp.pl?gene=TBX5. Accessed November 1, 2018.

9. Simon H. T-box genes and the formation of vertebrate forelimb- and hindlimb specific pattern. Cell Tissue Res. 1999;296(1):57-66.

10. Hatcher CJ, Goldstein MM, Mah CS, Delia CS, Basson CT. Identification and localization of TBX5 transcription factor during human cardiac morphogenesis. Dev Dyn. 2000;219(1):90-95.

11. Steimle JD, Moskowitz IP. TBX5: a key regulator of heart development. Curr Top Dev Biol. 2017;122:195-221.

12. Agarwal P, Wylie JN, Galceran J, et al. Tbx 5 is essential for forelimb bud initiation following patterning of the limb field in the mouse embryo. Development. 2003;130(3):623-633.

13. Kimura M, Kikuchi A, Ichinoi N, Kure S. Novel TBX5 duplication in a Japanese family with Holt-Oram syndrome. Pediatr Cardiol. 2015;36(1):244-247. 
14. Mori AD, Bruneau BG. TBX5 mutations and congenital heart disease: Holt-Oram syndrome revealed. Curr Opin Cardiol. 2004;19(3):211-215.

15. Fan C, Liu M, Wang Q. Functional analysis of TBX5 missense mutations associated with Holt-Oram syndrome. J Biol Chem. $2003 ; 278(10): 8780-8785$.

16. Li B, Chen S, Sun K, Xu R, Wu Y. Genetic Analyses Identified a SALL4 Gene Mutation Associated with Holt-Oram Syndrome. DNA Cell Biol. 2018;37(4):398-404.

17. Basson CT, Cowley GS, Solomon SD, et al. The clinical and genetic spectrum of the Holt-Oram syndrome (heart-hand syndrome. $N$ Engl J Med. 1994;330(13):885-891.

18. Smemo S, Campos LC, Moskowitz IP, Krieger JE, Pereira AC, Nobrega MA. Regulatory variation in a TBX5 enhancer leads to isolated congenital heart disease. Hum Mol Genet. 2012;21(14):3255-3263.

19. Stennard FA, Harvey RP. T-box transcription factors and their roles in regulatory hierarchies in the developing heart. Development. 2005;132(22):4897-4910.
20. Hatcher CJ, Mcdermott DA. Using the TBX 5 transcription factor to grow and sculpt the heart. Am JMed Genet part A. 2006;140(13):1414-1418.

21. ACMG. Genetics Evaluation Guidelines for the Etiologic Diagnosis of Congenital Hearing Loss. Genetic Evaluation of Congenital Hearing Loss Expert Panel. ACMG statement. Genet Med. 2002;4(3):162-171.

22. Brassington AM, Sung SS, Toydemir RM, et al. Expressivity of HoltOram syndrome is not predicted by TBX5 genotype. Am J Hum Genet. 2003;73(1):74-85.

23. Tseng YR, Yn S, Fl L. Holt-Oram syndrome with right lung agenesis caused by a de novo mutation in the TBX5 gene. Am J Med Genet Part A. 2007;143(9):1012-1014.

24. Garavelli L, de Brasi D, Verri R, et al. Holt-Oram syndrome associated with anomalies of the feet. Am J Med Genet Part A. 2008;146A(9):1185-1189.

25. Chin J, Pereira S, Camacho A, et al. Holt-Oram syndrome: a case report. Rev Port Cardiol. 2014;33(11):737.e1-5.
The Application of Clinical Genetics

\section{Publish your work in this journal}

The Application of Clinical Genetics is an international, peer-reviewed open access journal that welcomes laboratory and clinical findings in the field of human genetics. Specific topics include: Population genetics; Functional genetics; Natural history of genetic disease; Management of genetic disease; Mechanisms of genetic disease; Counselling and ethical
Dovepress

issues; Animal models; Pharmacogenetics; Prenatal diagnosis; Dysmorphology. The manuscript management system is completely online and includes a very quick and fair peer-review system, which is all easy to use. Visit http://www.dovepress.com/testimonials.php to read real quotes from published authors.

Submit your manuscript here: https://www.dovepress.com/the-application-of-clinical-genetics-journal 